\title{
In vitro ruminal dry matter and neutral detergent fibre digestibility of common feedstuffs as affected by the addition of essential oils and their active compounds
}

\author{
F. Righi' ${ }^{13}$, M. Simoni ${ }^{1}$, A. Foskolos ${ }^{2}$, V. Beretti' ${ }^{1}$ A. Sabbioni' and A. Quarantelli' \\ 1 University of Parma, Department of Veterinary Science, 43126 Parma, Italy \\ ${ }^{2}$ Aberystwyth University, Institute of Biological, Environmental and Rural Sciences (IBERS), \\ SY23 3EE, Gogerddan, Aberystwyth, United Kingdom
}

KEY WORDS: essential oils, fibre, dry matter, in vitro digestibility

Received: $\quad 16$ March 2017

Revised: 21 June 2017

Accepted: 11 September 2017

${ }^{3}$ Corresponding author:

e-mail: federico.righi@unipr.it

\begin{abstract}
The effects of essential oils (EO) and their active compounds (EOC) on dry matter digestibility and neutral detergent fibre digestibility (DMD and NDFD, respectively) are still not enough described since in vitro methods are limited. So, the aim of the study was to screen and compare the main effects of EO and EOC on short-term DMD and NDFD using the in vitro method. The addition of phenylpropanoid-rich cinnamon oil (CIN) and clove oil (CLO), terpenoid-rich thyme oil (THY) and oregano oil (ORG), and four EOC: cinnamaldehyde (CIN-C), eugenol (EUG), thymol (THY-C) and carvacrol (CAR) was studied at a dose of $0.5 \mathrm{mg} \cdot \mathrm{I}^{-1}$ of main active compound. Products were tested on four substrates: lucerne hay, soyabean meal, maize meal and a total mixed ration (TMR). Digestibility was determined at 4 and $24 \mathrm{~h}$ of fermentation. Both CIN and CIN-C increased NDFD4 of lucerne and maize meal, and decreased NDFD24 of soyabean meal; while CIN-C reduced NDF24 of TMR and CIN reduced DMD of soyabean at both examined hours. CLO and EUG decreased the NDFD24 of soyabean meal improving its DMD24. Also initial DMD of lucerne was increased by both these factors. Only CLO reduced NDFD24 of maize meal. Both THY and THY-C reduced DMD4 of soyabean meal; however only THY-C improved NDF4 of lucerne and reduced NDFD24 of soyabean meal and TMR. DMD24 of most substrates (except lucerne) was reduced by ORE, but not by CAR which improved NDFD4 of lucerne. The in vitro method was sensitive to variations in digestibility caused by EO and $E O C$, providing a promising approach for the incorporation of EO and EOC effects in systems for cattle diet formulation.
\end{abstract}

\section{Introduction}

Several feeding strategies to improve cattle productivity and efficiency have targeted rumen functioning. Among feed additives, special attention has been paid to essential oils (EO) and their active compounds (EOC; Calsamiglia et al., 2007). Either EO extracted from plant tissues with various concentrations of main compounds or purified EOC (natural or synthetic that are usually cheaper) are available on the market. The main benefit of EO and EOC is their antimicrobial activity. So, the addition of EO and EOC into herbivorous diets may modify rumen fermentation by inhibiting deamination and methanogenesis, resulting in lower ammonia$\mathrm{N}$, methane and acetate production, and in higher 
propionate and butyrate concentrations (Calsamiglia et al., 2007). These effects are dose-dependent higher doses may cause a severe reduction of fermentation processes in the rumen. Recently, it was demonstrated that propyl-propane thiosulfonate (PTSO), one of the main EOC derived from garlic oil, reduced by $33 \%$ the true organic matter digestibility in dual flow continuous culture fermenters only when higher dose was used ( $300 \mathrm{vs} 30 \mathrm{mg} \cdot 1^{-1}$ ) (Foskolos et al., 2015). However, this reduction was not accompanied by a similar reduction in neutral detergent fibre (NDF) digestibility (NDFD).

Using the in situ method, Pirondini et al. (2015) reported reduced NDFD in dry cows fed thymol and Nanon et al. (2014) reported no effects of garlic and ginger oil mixture supplementation in cows. Similarly, in in vivo study on cows supplemented a mixture of natural and nature-identical EO components that included thymol, eugenol, vanillin, and limonene, there was reported no effect on total tract NDFD (Benchaar et al., 2006). However other researchers reported a linear reduction of ruminal NDFD in duodenal cannulated cattle with increasing doses of eugenol (e.g., Yang et al., 2010). Surprisingly, Tekippe et al. (2013) stated that in cows supplemented with a blend of EOC based on eugenol and cinnamaldehyde total tract NDFD increased by $1.8 \%$ to $9.0 \%$. Certainly, these contradicting results reflect differences between the tested EOC, used doses (often not economically suitable for commercial livestock), as well as diet/substrate characteristics (Kilic et al., 2011), but may also reflect analytical differences either of the in situ method or the selected NDF analysis. The wide variation in methodologies analysing NDFD is well documented and in several studies differences between the in situ and the in vitro methods were reported (e.g., Spanghero et al., 2003; Bender et al., 2016). It appears that EO and EOC at a specific dose can exert a different effect on digestibility and this effect can be dependent on both fermented substrate and tested plant extract. Moreover, based on the available data, it is conceivable that NDFD and dry matter (DM) digestibility (DMD) can be affected differently and their combined interpretation can further explain the activity of these bioactive additives. Data on the effects of different doses added to diets of different energy concentration and composition have been reviewed by Hart et al. (2008) and recently by Cobellis et al. (2016); also some substrate effects were reported by Kilic et al. (2011) who examined gas production of barley, soyabean meal and wheat straw treated with different doses of oregano, black seed, laurel, cumin, garlic, anise and cinnamon EO. The effects of specific compounds were reported by various authors. According to Chaudhary et al. (2016) oregano and thyme EO decreased in vitro acetate production, while Mirzaei et al. (2016) obtained a decreased gas production using a Thymus kotschyanus EO containing $25.77 \%$ geraniol and $14.85 \%$ thymol. Moreover, Roy et al. (2015) demonstrated a depressive effect of thyme and clove EO on feed degradability and volatile fatty acid (VFA) production, while carvacrol and limonene significantly decreased digestibility of nutrients and VFA production (Hundal et al., 2016). In the same work, cinnamaldehyde was shown to increase total and individual VFA production. However, the reported results deal mainly with VFA production and fermentation products in general, without specific indications on NDFD and DMD evaluated on the basis of undigested residues. The latter are determined using the procedure described by Goering and Van Soest (1970), which is considered as the reference method to provide NDFD inputs for nutritional systems and models (Higgs et al., 2015; Van Amburgh et al., 2015). Therefore, the objective of the current study was to provide screening test of commercially used doses of EO and EOC related to their effects on short-term NDFD and DMD using the reference method for the main nutritional models on different substrates. The further objective was to compare the effects of EO and related EOC. The comparison between different EO and EOC actions was performed after their supplementation to different substrates to test the interaction between the main experimental factors and substrate. So, the overall aim was to evaluate EO and EOC effects that can be directly applied in the field.

\section{Material and methods}

The in vitro batch fermentation system as described by Goering and Van Soest (1970) was used to evaluate the effects of 4 EO and 4 corresponding EOC on short-term ruminal DM and NDF digestibility (DMD and NDFD, respectively) of 4 different substrates at 2 fermentation points (4 and 24 h; DMD4 and DMD24, and NDFD4 and NDFD24, respectively for DMD and NDFD at 4 and $24 \mathrm{~h}$ ). Analyses were conducted in duplicate and digestion trials were repeated twice on the same substrates using inoculum collected in two different weeks. The $4 \mathrm{~h}$-fermentation is above the interval estimated to be accurate as lag time by Van Amburgh et al. (2004) for the in vitro fermentation method 
employed and may be considered as indicative of the colonization pattern of the substrates by bacteria as well as their adaptation to the substrate. On the other hand, digestibility at $24 \mathrm{~h}$ of fermentation is considered as a significant time point since it better describes the potential digestibility of NDF in high producing lactating dairy cows (Van Amburgh et al., 2004). Treatments included a control (CTR; no addition of EO or EOC), 4 EO obtained from Muller \& Kostner (Liscate, Italy): phenylpropanoid-rich cinnamon oil (CIN; 72-82\% cinnamaldhyde) and clove oil (CLO; 70-83\% eugenol), terpenoid-rich thyme oil (THY; 41-43\% thymol) and oregano oil (ORE; 64-70\% carvacrol), and four EOC obtained from Frey and Lau (Henstedt-Ulzburg, Germany): cinnamaldhyde (CIN-C), eugenol (EUG), thymol (THY-C) and carvacrol (CAR). The selected EO and EOC were diluted in silica (Rhodia-Solvay, Bruxell, Belgium) to obtain a concentration of $0.125 \% \mathrm{wt} /$ wt of the main active compound. Based on in vivo studies conducted on dairy cattle (Benchaar et al., 2006), the adequate dose of the active compound was estimated as equivalent to $1 \mathrm{~g} / \mathrm{cow}$. Assuming DM intake of $20 \mathrm{~kg}$, the final concentration was set at $50 \mathrm{mg} \cdot \mathrm{kg}^{-1}$ of DM (equivalent to $0.5 \mathrm{mg} \cdot 1^{-1}$ taking into account a substrate of $0.5 \mathrm{~g}$ and $50 \mathrm{ml}$ of inoculum in each flask). Fermentation substrates (Table 1) included lucerne hay, soyabean meal, and maize meal to represent the main feed ingredients used as sources of fibre, protein and starch, respectively, and a total mixed ration (TMR) to represent a typical maize silage based diet of the Padana Plain - Northern Italy (Marseglia et al., 2013; Comino et al., 2015; Righi et al., 2016). Substrates were oven-dried at $55{ }^{\circ} \mathrm{C}$ for $48 \mathrm{~h}$ and ground in a Cyclotec mill (Tecator, Herndon, VA, USA) to pass a 1-mm screen.

Table 1. Nutrient composition of substrates

\begin{tabular}{lcccc}
\hline \multirow{2}{*}{ Nutrients, \% DM } & $\begin{array}{l}\text { Lucerne } \\
\text { hay }\end{array}$ & $\begin{array}{l}\text { Soyabean } \\
\text { meal }\end{array}$ & $\begin{array}{l}\text { Maize grain, } \\
\text { ground }\end{array}$ & TMR $^{1}$ \\
\hline Dry matter, \% & 86.5 & 89.6 & 88.2 & 47.5 \\
Crude protein & 17.0 & 45.7 & 9.8 & 16.8 \\
Ether extract & 1.4 & 2.8 & 4.1 & 4.1 \\
Starch & - & - & 68.1 & 29.3 \\
Ash & 9.4 & 6.9 & 1.7 & 6.2 \\
Neutral detergent fibre & 57.1 & 21.0 & 16.1 & 34.8 \\
Acid detergent fibre & 32.2 & 8.9 & 2.9 & 16.0 \\
Acid detergent lignin & 7.8 & 0.9 & 0.5 & 2.0 \\
\hline
\end{tabular}

${ }^{1}$ TMR - total mixed ration (\% DM), \%: maize silage 24.6 , triticale silage 10.8 , sorghum haylage 6.1 , lucerne hay 4.9 , wheat straw 1.0 , maize meal 18.0 , maize grain flaked 6.6 , barley meal 4.2 , soyabean meal 7.9 , soyabean flakes 2.0 , soyabean hulls 3.3 , maize distillers 3.8 , beet pulp 3.3, Megalac ${ }^{\circledR} 1.8$, mineral and vitamin premix 1.8
Detailed procedures were described by Comino et al. (2014). Briefly, rumen fluid was collected from a 6-year old Italian Holstein dry cow of about $660 \mathrm{~kg}$ live weight and fed $2 \mathrm{~kg}$ of concentrate (on a DM basis, \%: maize meal 36, maize germ meal 19, wheat flour 18 , sunflower meal 10 , wheat bran 6 , soyabean meal 3, sugarcane molasses 2.6, mineral and vitamin premix 5.4) per day. Animal had also ad libitum access to grass and lucerne hay $(55 \%$ NDF; $14 \%$ crude protein (CP)). The obtained rumen fluid was stirred and filtered through 4 layers of cheesecloth under continuous flushing of $\mathrm{CO}_{2}$. After filtration rumen fluid was mixed with the pre-incubated at $39^{\circ} \mathrm{C}$ Van Soest buffer at 1:4 ratio (Goering and Van Soest, 1970). Flasks containing the substrate $(0.5 \mathrm{~g})$ and treatments were inoculated with $50 \mathrm{ml}$ of diluted fluid. Two flasks per each treatment (EO or EOC), substrate and fermentation point were incubated at $39^{\circ} \mathrm{C}$ and the experiment was repeated twice for both DMD and NDFD.

Pre-selected flasks were removed at 4 and $24 \mathrm{~h}$ of incubation. In particular, 2 flasks for DM and 2 flasks for NDF analyses were used. DM was determined according to Righi et al. (2009): the fermentation content of each flask was filtered through crucibles (Robu Glass Filter-ROBU H3, Borosilicate 3.3, $30 \mathrm{ml}$ - Por. 2, Hattert, Germany), rinsed 3 times with boiling water and dried overnight at $105{ }^{\circ} \mathrm{C}$. For NDF determination, the fermentation content of each flask was transferred to a Raw Fiber Extractor (FIWE, VELP Scientifica, Usmate, Italy) and boiled with the addition of heatstable amylase (A3306, Sigma-Aldrich, St. Louis, MO, USA) for $1 \mathrm{~h}$; the residuals were then rinsed 3 times with boiling water and NDF was expressed on a DM basis including residual ash, as described by Van Soest et al. (1991). Then, DMD4, DMD24, NDF4 and NDFD24 were calculated by difference and expressed as a proportion of supply.

Dried substrates were analysed for $\mathrm{CP}$ and ether extract using the Soxhlet extraction system according to the European Commission regulation No. 152/2009 (European Commission, 2009). Ash content was determined by ignition to $550{ }^{\circ} \mathrm{C}$ and NDF was determined as described above. Concentration of starch was determined by polarimetric method, according the European Commission regulation No. 152/2009 (European Commission, 2009).

All statistical analyses were performed using the SPSS for Windows software package (version 21.0; SPSS Inc., Chicago, IL, USA). The differences between the treatments in DMD4, DMD24, NDFD4 and NDF24 of each substrate were tested separately 
using the univariate procedure of the General Linear Model, with treatment and period as fixed factors. The LSD post hoc test was applied to evaluate the statistical significance between treatments. Differences were declared significant at $P \leq 0.05$. Results were reported as least squares means.

\section{Results}

EO and EOC used in the study exerted different effects depending on the substrate (lucerne, soyabean meal, maize meal, TMR) as indicated by the significant interactions between treatment and substrate $(P<0.001-$ data not shown $)$, except for DMD4.

NDFD4 of lucerne increased $(P=0.047)$ by the addition of CAR $(+45.62 \%)$, THY-C $(+25.06 \%), \mathrm{CIN}$ $(+19.49 \%)$ and $\mathrm{CIN}-\mathrm{C}(+22.05 \%)$ in comparison with CTR. A similar effect of CIN and CIN-C was found in NDFD4 of maize meal $(+16.54 \%$ and $+14.37 \%$, respectively; $P=0.008$; Table 2 ).
The reducing effect on NDFD was observed usually at $24 \mathrm{~h}$ of fermentation and mainly on the tested concentrated feeds (soyabean meal and TMR). In comparison with CTR, NDFD24 of soyabean meal was decreased $(P=0.002)$ by CLO $(-11.57 \%)$ and EUG $(-10.96 \%)$ and, in a lower extent, by CIN $(-4.67 \%)$, THY-C $(-3.61 \%)$ and CIN-C $(-2.43 \%)$. Further, CLO has significantly depressed NDFD24 of maize meal $(-27.37 \%)$ as compared with CTR $(P<0.006)$; and a suppression of NDFD24 was exerted by CIN-C and THY-C on TMR $(-22.05 \%$ and $-10.32 \%$, respectively; $P<0.001)$. A different activity was found between CIN and CIN-C, and THY and THY-C on TMR NDFD24, as only CIN-C and THY-C reduced this parameter. Moreover, CAR caused the highest lucerne NDFD4 in contrast with ORE that had no effect.

The addition of most EO and EOC significantly depressed DMD4 of soyabean meal $(P<0.001$; Table 3 ), with values ranging from $-19.72 \%$ for CIN to $-13.85 \%$ for THY-C in comparison with CTR.

Table 2. Effect of essential oils (EO) and essential oil compounds (EOC) on in vitro neutral detergent fibre (NDF) digestibility (\% NDF) of lucerne, soyabean meal, maize meal and total mixed ration $(T M R)^{1}$ at 4 and $24 \mathrm{~h}$ of fermentation ${ }^{2}$

\begin{tabular}{lclllllllllll}
\hline Feedstuffs & Interval & CTR & CIN & CIN-C & CLO & EUG & THY & THY-C & ORE & CAR & SEM & $P$-value \\
\hline Lucerne & 4 & $19.55^{\mathrm{a}}$ & $23.36^{\mathrm{b}}$ & $23.86^{\mathrm{b}}$ & $20.42^{\mathrm{ab}}$ & $19.87^{\mathrm{a}}$ & $20.61^{\mathrm{ab}}$ & $24.45^{\mathrm{b}}$ & $19.53^{\mathrm{a}}$ & $28.47^{\mathrm{c}}$ & 0.750 & 0.047 \\
& 24 & 44.75 & 44.08 & 44.32 & 47.42 & 45.62 & 44.19 & 41.96 & 43.94 & 48.68 & 0.463 & 0.153 \\
Soyabean meal & 4 & 48.52 & 45.43 & 51.61 & 48.95 & 47.00 & 51.08 & 54.58 & 49.71 & 54.48 & 0.809 & 0.102 \\
& 24 & $98.66^{\mathrm{c}}$ & $94.05^{\mathrm{b}}$ & $96.26^{\mathrm{b}}$ & $87.24^{\mathrm{a}}$ & $87.85^{\mathrm{a}}$ & $98.82^{\mathrm{c}}$ & $95.10^{\mathrm{b}}$ & $99.46^{\mathrm{c}}$ & $99.70^{\mathrm{c}}$ & 1.125 & 0.002 \\
Maize meal & 4 & $58.10^{\mathrm{ab}}$ & $67.71^{\mathrm{c}}$ & $66.45^{\mathrm{c}}$ & $57.91^{\mathrm{ab}}$ & $59.83^{\mathrm{ab}}$ & $55.35^{\mathrm{a}}$ & $60.61^{\mathrm{b}}$ & $59.38^{\mathrm{ab}}$ & $56.66^{\mathrm{ab}}$ & 0.999 & 0.008 \\
& 24 & $94.83^{\mathrm{b}}$ & $91.53^{\mathrm{b}}$ & $88.88^{\mathrm{b}}$ & $68.87^{\mathrm{a}}$ & $84.09^{\mathrm{ab}}$ & $87.95^{\mathrm{ab}}$ & $88.07^{\mathrm{ab}}$ & $86.23^{\mathrm{ab}}$ & $92.69^{\mathrm{b}}$ & 1.587 & 0.006 \\
TMR & 4 & 34.38 & 35.01 & 33.98 & 37.35 & 34.96 & 35.48 & 34.96 & 35.59 & 38.06 & 0.438 & 0.845 \\
& 24 & $69.99^{\mathrm{cd}}$ & $70.93^{\mathrm{d}}$ & $54.56^{\mathrm{a}}$ & $74.24^{\mathrm{d}}$ & $70.11^{\mathrm{bcd}}$ & $64.55^{\mathrm{c}}$ & $62.77^{\mathrm{b}}$ & $72.14^{\text {cd }}$ & $67.87^{\text {cd }}$ & 1.513 & $<0.001$ \\
\hline
\end{tabular}

${ }^{1}$ TMR - see Table $1 ;{ }^{2}$ concentrations of EO (CIN - cinnamon; CLO - cloves; THY - thyme; ORE - oregano) and EOC (CIN-C - cinnamaldehyde; EUG - eugenol; THY-C - thymol; CAR - carvacrol) were adjusted to obtain a concentration $0.5 \mathrm{mg} \cdot \mathrm{l}^{-1}$ of the main active compound; ${ }^{\mathrm{a}-\mathrm{d}}-$ values with different superscripts within substrate and time are significantly different at $P<0.05$; significance of difference between periods is not reported

Table 3. Effect of essential oils (EO) and essential oil compounds (EOC) on in vitro dry matter (DM) digestibility of lucerne, soyabean meal, maize meal and total mixed ration $(T M R)^{1}$ at 4 and $24 \mathrm{~h}$ of fermentation ${ }^{2}$

\begin{tabular}{lclllllllllll}
\hline Feedstuffs & Interval & CTR & CIN & CIN-C & CLO & EUG & THY & THY-C & ORE & CAR & SEM & $P$-value \\
\hline Lucerne & 4 & $30.98^{\mathrm{a}}$ & $32.56^{\mathrm{ab}}$ & $34.94^{\mathrm{bc}}$ & $35.96^{\mathrm{c}}$ & $36.42^{\mathrm{c}}$ & $32.22^{\mathrm{ab}}$ & $30.43^{\mathrm{a}}$ & $29.74^{\mathrm{a}}$ & $32.57^{\mathrm{ab}}$ & 0.460 & $<0.001$ \\
& 24 & $49.58^{\mathrm{abcd}}$ & $47.29^{\mathrm{bd}}$ & $47.40^{\mathrm{abcd}}$ & $50.21^{\mathrm{d}}$ & $47.24^{\mathrm{bd}}$ & $45.75^{\mathrm{bc}}$ & $44.37^{\mathrm{ab}}$ & $40.47^{\mathrm{a}}$ & $44.98^{\mathrm{b}}$ & 0.629 & 0.030 \\
Soyabean meal & 4 & $59.69^{\mathrm{c}}$ & $47.92^{\mathrm{a}}$ & $57.65^{\mathrm{c}}$ & $54.20^{\mathrm{bc}}$ & $56.60^{\mathrm{bc}}$ & $48.43^{\mathrm{a}}$ & $51.42^{\mathrm{ab}}$ & $49.74^{\mathrm{ab}}$ & $49.25^{\mathrm{ab}}$ & 0.817 & $<0.001$ \\
& 24 & $87.48^{\mathrm{cd}}$ & $81.68^{\mathrm{b}}$ & $86.66^{\mathrm{cd}}$ & $91.65^{\mathrm{e}}$ & $91.91^{\mathrm{e}}$ & $84.68^{\mathrm{bc}}$ & $89.39^{\mathrm{de}}$ & $76.70^{\mathrm{a}}$ & $89.79^{\mathrm{de}}$ & 1.117 & $<0.001$ \\
Maize meal & 4 & 53.73 & 54.82 & 57.55 & 50.25 & 45.64 & 58.44 & 51.13 & 55.29 & 49.16 & 0.861 & 0.216 \\
& 24 & $88.31^{\mathrm{b}}$ & $87.22^{\mathrm{b}}$ & $87.64^{\mathrm{b}}$ & $88.65^{\mathrm{b}}$ & $84.65^{\mathrm{ab}}$ & $85.22^{\mathrm{ab}}$ & $85.21^{\mathrm{ab}}$ & $80.70^{\mathrm{a}}$ & $89.50^{\mathrm{b}}$ & 0.533 & 0.003 \\
TMR & 4 & 46.14 & 46.33 & 46.51 & 44.40 & 46.52 & 42.87 & 41.88 & 43.76 & 44.24 & 0.433 & 0.286 \\
& 24 & $71.95^{\mathrm{b}}$ & $75.26^{\mathrm{b}}$ & $73.84^{\mathrm{b}}$ & $76.11^{\mathrm{c}}$ & $73.05^{\mathrm{b}}$ & $74.94^{\mathrm{b}}$ & $75.38^{\mathrm{bc}}$ & $61.56^{\mathrm{a}}$ & $75.78^{\mathrm{b}}$ & 0.826 & $<0.001$ \\
\hline
\end{tabular}

${ }^{1} \mathrm{TMR}$ - see Table $1 ;{ }^{2}$ concentrations of EO (CIN - cinnamon; CLO - cloves; THY - thyme; ORE - oregano) and EOC (CIN-C - cinnamaldehyde; EUG - eugenol; THY-C - thymol; CAR - carvacrol) were adjusted to obtain a concentration $0.5 \mathrm{mg} \cdot \mathrm{l}^{-1}$ of the main active compound; ${ }^{\text {a-d }}$ - values with different superscripts within substrate and time are significantly different at $P<0.05$; significance of difference between periods is not reported 
The addition of CIN and ORE reduced DMD24 of soyabean meal $(P=0.001)$. In addition, ORE reduced also DMD24 of ground maize grain $(P=0.003)$ and TMR $(P=0.001)$. Interestingly, DMD24 of soyabean meal was increased by the addition of CLO $(+4.77 \%)$ and EUG $(+5.06 \%)$ as compared with CTR. A different effect was found between CIN and CIN-C on DMD of soyabean meal at both intervals, with CIN reducing this parameter and $\mathrm{CIN}-\mathrm{C}$ showing no effect on digestibility. In comparison to CTR the ORG decreased and CLO increased DMD24 of TMR $(P<0.001)$, no such effects of EOC of these EO were observed.

\section{Discussion}

Due to the evidence that EO and EOC can exert different effects on digestibility depending on the fermented substrate, the present study was designed to screen some selected EO and EOC in relationship to their effects on short-term DMD and NDFD of different substrates. As previously reported, the reference in vitro method usually employed to provide NDFD inputs for nutritional systems was used considering a possible future application of the results in diet formulation models. Also, the study was conducted to evaluate in vitro DMD and general effects of the tested EO and EOC on overall substrate degradation.

In general, the effects of used EO and EOC were different and substrate-dependent. Such finding is in agreement with Kilic et al. (2011) who demonstrated different effects of oregano, black seed, laurel, cumin, garlic, anise and cinnamon EO on barley, soyabean and wheat straw using the gas production technique. Similarly, Khiaosa-ard and Zebeli (2014) recommended to pay attention to diet composition and supplementation period in evaluating the effects of EO and EOC in ruminants, indicating better effect of EO in general in low NDF diets inducing lower ruminal $\mathrm{pH}$. The same authors observed in beef cattle greater response to the generality of EO and their bioactive compounds than in dairy cattle and small ruminants. This result was related to as additive synergistic effect of low ruminal $\mathrm{pH}$ and/or a more consistent diet composition. It was found that in beef cattle EUG addition decreased NDF and CP ruminal degradation and reduced acetate:propionate ratio showing some potential to increase growth rate in beef cattle (Yang et al., 2010) but in dairy cattle EUG failed to modify digestion, ruminal fermentation and microbial populations demonstrating a low potential for using it as additive to dairy cow diet (Benchaar et al., 2012).
Moreover, Kilic et al. (2011) showed a reducing activity of various doses of ORE on barley and straw. This is consistent with our results obtained for maize meal and TMR; nevertheless the effect of ORE and CIN on soyabean meal was not observed like in our study.

Results of the present study show variable effects of the tested products on both NDFD and DMD. It appears that NDFD was positively affected mainly at $4 \mathrm{~h}$ of fermentation, indicating a probable positive effect on fibre bacterial colonization, possibly related to an increased microbial attachment of bacteria to feed particles, or to a reduction in nonstructural carbohydrate fermenting bacteria populations. Nanon et al. (2014) used ${ }^{15} \mathrm{~N}$ as microbial marker to investigate ruminal microbial attachment and reported increased attachment for lemongrass EO supplemented cows in comparison with a mixture of garlic and ginger oil. Further, this improvement of NDFD and DMD was partly attributed to the increased attachment. Lemongrass oil is an aldehyde-based oil, like CIN which contains CIN-C. Therefore, they possibly possess a similar mode of action in the rumen. Even though the ruminal microbial attachment was not measured directly, the $4 \mathrm{~h}$ fermentation was used as an indicator of microbial attachment and lag time impact on the whole process (Van Amburgh et al., 2004). Therefore, our results may suggest that CIN and CIN-C improved microbial attachment resulting in reduced lag time and improved NDFD4 of lucerne and maize grain. A positive effect of CIN and CIN-C on both NDFD and organic matter digestibility after $24 \mathrm{~h}$ of fermentation was reported by Hundal et al. (2016) at levels higher than $1 \%$ of substrate DM using wheat straw as substrate. Although the in vitro method employed in this study differed from the one adopted in the present trial, the general indication can be considered consistent with our results.

Even though EOC have reduced selectivity against bacteria (Calsamiglia et al., 2007), some bacterial populations are more sensitive than others. For example, bacterial specificity of CIN-C against Prevotella spp. has been documented (Ferme et al., 2004). Therefore, the differences observed at $4 \mathrm{~h}$ of fermentation may suggest that non-structural carbohydrate bacteria are more susceptible to the antimicrobial activity than cellulolytic bacteria, allowing an increased NDFD in early fermentation times. As bacteria number and species were not investigated in the present study, no objective data are available to support the latter hypothesis. Moreover, Patra and Yu (2012) reported that the Shannon-Wiener 
diversity index of bacteria increased with low and medium doses $\left(0.25\right.$ and $\left.0.50 \mathrm{~g} \cdot \mathrm{l}^{-1}\right)$ of CLO oil at $24 \mathrm{~h}$ of in vitro fermentation and this is consistent with the initial effect induced by CIN-C, CLO and EUG on DMD4 of lucerne. In this direction CAR exerted the strongest effect on NDFD4 of lucerne, probably in relationship to a more effective antimicrobial activity than other terpenoids attributable to the presence of methyl ether group on its molecule (Nazzaro et al., 2013) and this could have indirectly affected NDFD4 of lucerne.

CIN-C and EUG-containing products at $500 \mathrm{mg} \cdot \mathrm{d}^{-1}$ were found to increase total tract NDFD of dairy cows fed TMR(Tekippe etal., 2013); CLO was shown to increase in vitro DM and NDF digestibility at the dose of $300 \mathrm{ppm}$ (Rofiq and Gorgulu, 2014). Moreover, irrespective of the level employed (1-5\% of substrate DM), CIN-C was found to increase NDF and organic matter digestibility along with VFA and net gas production from wheat straw inoculated with ram rumen fluid (Hundal et al, 2016). This result was not supported by our data showing a reducing effect of CIN-C on TMR NDFD24 and a lack of effect of CIN, CLO and EUG. A lack of effects was found by Khateri et al. (2017), that demonstrated no effect of a blend including CLO and CIN (together with THY) on in vivo sheeps (fed a 50:50 forage to concentrate ratio diet) apparent total tract digestibility of $\mathrm{DM}$, $\mathrm{CP}$, organic matter, and NDF. Moreover, CLO appeared to reduce NDFD24 of soyabean meal and maize grain, while EUG decreased only the NDFD4 of soyabean meal. This is in agreement with Yang et al. (2010) who found a linear decrease in ruminal in vivo NDFD with increasing dose of EUG from 400 to $1600 \mathrm{mg} \cdot \mathrm{d}^{-1}$. The inhibitory effects on fibre degradation caused by EUG and partially by CLO on soyabean and maize meal at $24 \mathrm{~h}$ of fermentation are supported by the mitigation of methane production reported by Joch et al. (2016), even if on TMR (70:30 forage to concentrate substrate ratio) at the same interval with $1000 \mathrm{ppm}$ of EOC. This could be partially explained by the reduction of the hemicellulose fraction operated by the contact of CLO at 100 and 200 ppm with wheat straw cell wall found by Özelçam et al. (2017). Similarly, Roy et al. (2015) tested the in vitro activity of $600 \mathrm{ppm}$ of CLO on high roughage diet digested on buffalo rumen liquor, demonstrating a depressive effect of the treatment on total gas production, organic matter and DM degradability, total VFA and acetate:propionate ratio. These results are not confirmed by our data on CLO or EUG supplemented lucerne and TMR degradability.
Evans and Martin (2000) demonstrated a reduction of methane and acetate - main products of fibre fermentation, treating rumen fluid with $400 \mathrm{mg} \cdot 1^{-1}$ of THY-C. This appears to be consistent with the results of the present work showing a detrimental effect of THY-C on NDFD24 of TMR. Similar results were obtained by Pirondini et al. (2015) who reported a reduced in situ and total tract NDFD of dry cows supplemented with $5 \mathrm{~g} \cdot \mathrm{d}^{-1}$ of THY-C. A decrease in acetate percentage was examined in vitro for THY-C on high fibre diet by Chaudhary et al. (2016) and this could indicate a reduction in fibre digestibility. In summary, the negative effects on the NDFD24 were exerted mainly by phenylpropanoid-rich EO and EOC added to tested concentrate feeds and TMR, and by THY-C added to TMR. This effect should be mainly related to the antimicrobial properties of these compounds that could also be exacerbated in the steady state system employed to test digestibility at the continuous and constant contact between bacteria and products.

The addition of ORE decreased DMD4 and DMD24 of soyabean as well as DMD24 of maize meal and TMR. This is consistent with findings of Kilic et al. (2011) who observed a decreased gas production using ORE on barley, soyabean and wheat straw. Moreover, CAR depressed DMD4 of soyabean in the present study. Testing the activity of ORE and CAR at two doses $\left(200\right.$ and $\left.400 \mathrm{mg} \cdot 1^{-1}\right)$ and using a TMR as a substrate, Benchaar et al. (2007) reported a depressive effect of these products on both in vitro DMD and total gas production. In addition, CAR was found by Joch et al. (2016) to reduce in vitro methane and VFA production from a 70:30 forage:concentrate diet at the dose of about $1 \mathrm{mg} \cdot 1^{-1}$ while methane production and acetate percentage were reduced in high fibre diet fermentation in a study by Chaudhary et al. (2016), that tested in vitro effect of ORE on wheat straw-based diets. Moreover, ORE was found to decrease the concentration of ammonia at doses from 30 to $300 \mathrm{mg} \cdot 1^{-1}$ (Cardozo et al., 2005), indicating a depressing effect on proteolytic activity. This reducing effect on protein degradation could be more evident on substrates containing high amount of proteins, such as soyabean meal.

Interestingly, CLO and EUG appeared to increase DMD4 of lucerne and DMD24 of soyabean meal. In contrast, Benchaar et al. (2007) reported a depressive activity on both gas production and in vitro DMD using $200 \mathrm{mg} \cdot 1^{-1}$ of CLO or $800 \mathrm{mg} \cdot 1^{-1}$ of EUG on a TMR diet, and Patra and Yu (2012) reported a reduced DMD of a complete diet with doses ranging from 250 to $1000 \mathrm{mg} \cdot 1^{-1}$. However, in the 
current study EO and EOC were added at a dose of $0.5 \mathrm{mg} \cdot 1^{-1}$-a minimal dose in comparison with other in vitro studies that supplied EOC up to 3000 (Busquet et al., 2006) or even $5000 \mathrm{mg} \cdot \mathrm{l}^{-1}$ (Castillejos et al., 2006). Such a low dose was chosen basing on in vivo studies in order to be equivalent to about $1 \mathrm{~g} / \mathrm{cow}-$ both for the economic sustainability of EO and EOC usage in dairy production and the inconsistencies between in vitro and in vivo studies reported in the literature. It could be argued that at the low levels employed in the present trial these molecules exert no or positive effect on DMD. Depressive effects on DMD were observed by Pawar et al. (2014) in a study on the effect of clove bud and leaf essential oils at doses similar to the doses employed in the present trial $\left(300\right.$ to $\left.800 \mu \mathrm{g} \cdot 1^{-1}\right)$. The study was however conducted on a complete diet (50:50 forage:concentrate ratio) fermentation, as reviewed by Cobellis et al. (2016).

Most EO that significantly affected NDFD and DMD showed a similar activity in comparison with their EOC. For example, CLO and EUG affected in the same way DMD4 of lucerne or DMD24 of soyabean meal. However, several differences between EO and EOC were detected. In the case of ORE and CAR the EO showed some effects on DMD while the active compound (CAR) did not. For example, DMD24 of almost all the tested substrates (except lucerne) was reduced by the addition of ORE, but not by the addition of CAR. Also CLO reduced NDFD24 of maize meal whereas EUG did not. An opposite trend was observed by Benchaar et al. (2007), who reported a reducing effect of CAR and no effect of ORE on DMD and gas production, and a more pronounced effect of EUG than CLO on NDFD at $24 \mathrm{~h}$ of in vitro incubation. It should be considered, however, that the cited trial was conducted only on TMR and the rumen fluid inoculum was collected from ruminally fistulated cows fed a high concentrate diet and this could partially explain the inconsistency of the results. In agreement with Benchaar et al. (2007) are the results found for CIN-C that reduced NDFD of TMR at $24 \mathrm{~h}$ of fermentation, and CIN that did not exert any effect on this parameter. Up to a certain level the differences between EO and EOC are expected because oils are complex mixtures of more than one compound. The EO of THY for example contains THY-C and CAR, while ORE contains mainly CAR but also THY-C (Calsamiglia et al., 2007). The multiplicity of active compounds found in EO did not appear to increase the activity of the additive in the case of THY, since THY-C increased NDFD4 of lucerne and reduced NDFD24 of soyabean meal differently from THY that did not affect these substrates digestion. THY and THY-C had similar properties in the study of Benchaar et al. (2007). It should be noted that in the present study the effective concentration of EO was calculated based on their principal compound; for example, THY and THY-C have the same concentration of THY-C. Despite some blends of EO (Khateri et al., 2017) and EOC (Newbold et al., 2004) have been tested in vivo and in vitro (Castillejos et al., 2005 ) with generally depressing or no effect on fermentations, we are not aware of any study examining the interactions between compounds; however our results suggest that interactions of compounds of EO may occur indicating or not an additive effect. In this direction are the results of Rofiq and Gorgulu (2014), who found an antagonistic effects between CLO and orange peel oil at $300 \mathrm{ppm}$ when they were used together in combination treatment for in vitro digestion of dairy TMR. Some interactions seem to emerge also by the analysis of the data reviewed by Simitzis (2017) on the action of EO alone and in mixture of EO and EOC in lamb/sheeps and dairy cattle ruminal parameters.

\section{Conclusions}

Essential oils (EO) and their main compounds (EOC) tested at commercially employed doses showed variable effects on different evaluated substrates (lucerne, soyabean meal, maize meal and total mixed ration). Also some differences between used EO and their corresponding EOC were found. Independently from the absolute variations in fibre and dry matter digestibility, the tested in vitro approach based on undigested residues seems to be promising and sensitive to variations in digestibility, providing data directly applicable in the field. In vivo studies and in situ digestibility trials could be of interest to confirm the measured effects of EO and EOC at the tested doses.

A rational implementation of these results should involve the correction of the rate of digestion of feeds fibre based on in vitro data, the application of the adjusted rates in diet formulation and the following in vivo validation of the nutritive values estimated under field/controlled conditions.

\section{Acknowledgements}

The present work was performed through the Programma Operativo Regionale (POR) 2007-2013 del Fondo Sociale Europeo (FSE), in collaboration with Biotrade di Malavasi Claudio \& C. SNC (Modena, Italy). Andreas Foskolos was supported 
by the Welsh Government and Higher Education Funding Council for Wales through the Sêr Cymru National Research Network for Low Carbon, Energy and Environment (Project: 'Cleaner Cows').

\section{References}

Benchaar C., Lettat A., Hassanat F., Yang W.Z., Forster R.J., Petit H.V., Chouinard P.Y., 2012. Eugenol for dairy cows fed low or high concentrate diets: Effects on digestion, ruminal fermentation characteristics, rumen microbial populations and milk fatty acid profile. Anim. Feed Sci. Technol. 178, 139-150, https:// doi.org/10.1016/j.anifeedsci.2012.10.005

Benchaar C., Petit H.V., Berthiaume R., Ouellet D.R., Chiquette J., Chouinard P.Y., 2007. Effects of essential oils on digestion, ruminal fermentation, rumen microbial populations, milk production, and milk composition in dairy cows fed alfalfa silage or corn silage. J. Dairy Sci. 90, 886-897, https://doi. org/10.3168/jds.S0022-0302(07)71572-2

Benchaar C., Petit H.V., Berthiaume R., Whyte T.D., Chouinard P.Y., 2006. Effects of addition of essential oils and monensin premix on digestion, ruminal fermentation, milk production, and milk composition in dairy cows. J. Dairy Sci. 89, 4352-4364, https://doi.org/10.3168/jds.S0022-0302(06)72482-1

Bender R.W., Cook D.E., Combs D.K., 2016. Comparison of in situ versus in vitro methods of fiber digestion at 120 and 288 hours to quantify the indigestible neutral detergent fiber fraction of corn silage samples. J. Dairy Sci. 99, 5394-5400, https://doi. org/10.3168/jds.2015-10258

Busquet M., Calsamiglia S., Ferret A., Kamel C., 2006. Plant extracts affect in vitro rumen microbial fermentation. J. Dairy Sci. 89, 761-771, https://doi.org/10.3168/jds.S0022-0302(06)72137-3

Calsamiglia S., Busquet M., Cardozo P.W., Castillejos L., Ferret A., 2007. Invited review: Essential oils as modifiers of rumen microbial fermentation. J. Dairy Sci. 90, 2580-2595, https://doi. org/10.3168/jds.2006-644

Cardozo P.W., Calsamiglia S., Ferret A., Kamel C., 2005. Screening for the effects of natural plant extracts at different $\mathrm{pH}$ on in vitro rumen microbial fermentation of a high-concentrate diet for beef cattle. J. Anim. Sci. 83, 2572-2579, https://doi.org/10.2527/2005.83112572x

Castillejos L., Calsamiglia S., Ferret A., 2006. Effect of essential oil active compounds on rumen microbial fermentation and nutrient flow in in vitro systems. J. Dairy Sci. 89, 2649-2658, https://doi.org/10.3168/jds.S0022-0302(06)72341-4

Castillejos L., Calsamiglia S., Ferret A., Losa R., 2005. Effects of a specific blend of essential oil compounds and the type of diet on rumen microbial fermentation and nutrient flow from a continuous culture system. Anim. Feed Sci. Technol. 119, 29-41, https://doi.org/10.1016/j.anifeedsci.2004.12.008

Chaudhary P.P., Goel N., Baker G., Saxena J., Singh N., Chaturvedi I., Sharma A., Sirohi S.K., 2016. Influence of essential oils supplementation on rumen fermentation profile and ruminal microbial population in vitro. J. Sci. 1(4), 25-34

Cobellis G., Trabalza-Marinucci M., Yu Z., 2016. Critical evaluation of essential oils as rumen modifiers in ruminant nutrition: $A$ review. Sci. Total Environ. 545-546, 556-568, https://doi.org/10.1016/j.scitotenv.2015.12.103

Comino L., Righi F., Coppa M., Quarantelli A., Tabacco E., Borreani G., 2015. Relationships among early lactation milk fat depression, cattle productivity and fatty acid composition on intensive dairy farms in northern Italy. Ital. J. Anim. Sci. 14, 3656 https://doi.org/10.4081/ijas.2015.3656
Comino L., Tabacco E., Righi F., Revello-Chion A., Quarantelli A., Borreani G., 2014. Effects of an inoculant containing a Lactobacillus buchneri that produces ferulate-esterase on fermentation products, aerobic stability, and fibre digestibility of maize silage harvested at different stages of maturity. Anim. Feed Sci. Technol. 198, 94-106, https://doi.org/10.1016/j. anifeedsci.2014.10.001

European Commission (EC), 2009. Commission Regulation (EC) No 152/2009 of 27 January 2009 laying down methods of sampling and analysis for the official control of feed. Off. J. EU 2009, L54/1-L54/130

Evans J.D., Martin S.A., 2000. Effects of thymol on ruminal microorganisms. Curr. Microbiol. 41, 336-340, https://doi.org/10.1007/ s002840010145

Ferme D., Banjac M., Calsamiglia S., Busquet M., Kamel C., Avguštin G., 2004. The effects of plant extracts on microbial community structure in a rumen-simulating continuous-culture system as revealed by molecular profiling. Folia Microbiol. (Praha) 49, 151-155, https://doi.org/10.1007/BF02931391

Foskolos A., Siurana A., Rodriquez-Prado M., Ferret A., Bravo D., Calsamiglia S., 2015. The effects of a garlic oil chemical compound, propyl-propane thiosulfonate, on ruminal fermentation and fatty acid outflow in a dual-flow continuous culture system. J. Dairy Sci. 98, 5482-5491, https://doi.org/10.3168/ jds.2014-8674

Goering K.H., Van Soest P.J., 1970. Forage Fiber Aanalyses (Apparatus, Reagents, Procedures and Some Applications). Agricultural Handbook No. 379. Agricultural Research Service - United States Department of Agriculture. Washington, DC (USA)

Hart K.J., Váñez-Ruiz D.R., Duval S.M., McEwan N.R., Newbold C.J., 2008. Plant extracts to manipulate rumen fermentation. Anim. Feed Sci. Technol. 147, 8-35, https://doi.org/10.1016/j.anifeedsci.2007.09.007

Higgs R.J., Chase L.E., Ross D.A., Van Amburgh M.E., 2015. Updating the Cornell Net Carbohydrate and Protein System feed library and analyzing model sensitivity to feed inputs. J. Dairy Sci. 98, 6340-6360, https://doi.org/10.3168/jds.2015-9379

Hundal J.S., Wadhwa M., Bakshi M.P.S., 2016. Effect of supplementing essential oils on the in vitro methane production and digestibility of wheat straw. J. Anim. Res. Nutr. 1, 14, https:// doi.org/10.21767/2572-5459.100014

Joch M., Cermak L., Hakl J., Hucko B., Duskova D., Marounek M., 2016. In vitro screening of essential oil active compounds for manipulation of rumen fermentation and methane mitigation. Asian-Australas. J. Anim. Sci. 29, 952-959, https://doi. org/10.5713/ajas.15.0474

Khateri N., Azizi O., Jahani-Azizabadi H., 2017. Effects of a specific blend of essential oils on apparent nutrient digestion, rumen fermentation and rumen microbial populations in sheep fed a 50: 50 alfalfa hay: concentrate diet. Asian-Australas. J. Anim. Sci. 30, 370-378, https://doi.org/10.5713/ajas.15.0865

Khiaosa-ard R., Zebeli Q., 2013. Meta-analysis of the effects of essential oils and their bioactive compounds on rumen fermentation characteristics and feed efficiency in ruminants. J. Anim. Sci. 91, 1819-1830, https://doi.org/10.2527/jas.2012-5691

Kilic U., Boga M., Gorgulu M., Şahan Z., 2011. The effects of different compounds in some essential oils on in vitro gas production. J. Anim. Feed Sci. 20, 626-636, https://doi.org/10.22358/ jafs/66221/2011

Marseglia A., Caligiani A., Comino L., Righi F., Quarantelli A., Palla G., 2013. Cyclopropyl and $\omega$-cyclohexyl fatty acids as quality markers of cow milk and cheese. Food Chem. 140, 711-716, https://doi.org/10.1016/j.foodchem.2013.01.029 
Mirzaei Z., Hozhabri F., Alipour D., 2016. Thymus kotschyanus essential oil components and their effects on in vitro rumen fermentation, protozoal population and acidosis parameters. Iranian J. Appl. Anim. Sci. 6, 77-85

Nanon A., Suksombat W., Yang W.Z., 2014. Effects of essential oils supplementation on in vitro and in situ feed digestion in beef cattle. Anim. Feed Sci. Technol. 196, 50-59, https://doi.org/10.1016/j.anifeedsci.2014.07.006

Nazzaro F., Fratianni F., De Martino L., Coppola R., De Feo V., 2013. Effect of essential oils on pathogenic bacteria. Pharmaceuticals 6, 1451-1474, https://doi.org/10.3390/ph6121451

Newbold C.J., Mclntosh F.M., Williams P., Losa R., Wallace R.J., 2004. Effects of a specific blend of essential oil compounds on rumen fermentation. Anim. Feed Sci. Technol. 114, 105-112, https://doi.org/10.1016/j.anifeedsci.2003.12.006

Özelçam H., Özüretmen S., İp̧ak H.H., Dereboylu A., 2017. The effect of clove essential oil treatment on the cell wall components of wheat straw. J. Agric. Sci. Technol. A 7, 68-72, https://doi. org/10.17265/2161-6256/2017.01.010

Patra A.K., Yu Z., 2012. Effects of essential oils on methane production and fermentation by, and abundance and diversity of rumen microbial populations. Appl. Environ. Microbiol. 78 , 4271-4280, https://doi.org/10.1128/AEM.00309-12

Pawar M.M., Kamra D.N., Agarwal N., Chaudhary L.C., 2014. Effects of essential oils on in vitro methanogenesis and feed fermentation with buffalo rumen liquor. Agric. Res. 3, 67-74, https://doi.org/10.1007/s40003-014-0092-z

Pirondini M., Colombini S., Malagutti L., Rapetti L., Galassi G., Zanchi R., Crovetto G.M., 2015. Effects of a selection of additives on in vitro ruminal methanogenesis and in situ and in vivo NDF digestibility. Anim. Sci. J. 86, 59-68, https://doi. org/10.1111/asj.12249

Righi F., Romanelli S., Renzi M., Quarantelli A., 2009. "In vivo" and "in vitro" degradability of diets for Parmigiano Reggiano cheese production. Ital. J. Anim. Sci. 8, 331-333, https://doi. org/10.4081/ijas.2009.s2.331

Righi F., Simoni M., Malacarne M., Summer A., Costantini E., Quarantelli A., 2016. Feeding a free choice energetic mineral-vitamin supplement to dry and transition cows: effects on health and early lactation performance. Large Anim. Rev. 22, 161-170
Rofiq M.N., Gorgulu M., 2014. Combination effect of clove and orange peel oils on in vitro digestion of $d$ total mixed ration using ANKOM DAISY" incubator. J. Adv. Agric. Technol. 1, 14-18, https://doi.org/10.12720/joaat.1.1.14-18

Roy D., Tomar S.K., Kumar V., 2015. Rumen modulatory effect of thyme, clove and peppermint oils in vitro using buffalo rumen liquor. Vet. World 8, 203-207, https://doi.org/10.14202/ vetworld.2015.203-207

Spanghero M., Boccalon S., Gracco L., Gruber L., 2003. NDF degradability of hays measured in situ and in vitro. Anim. Feed Sci. Technol. 104, 201-208, https://doi.org/10.1016/ S0377-8401(02)00327-9

Tekippe J.A., Tacoma R., Hristov A.N., Lee C., Oh J., Heyler K.S., Cassidy T.W., Varga G.A., Bravo D., 2013. Effect of essential oils on ruminal fermentation and lactation performance of dairy cows. J. Dairy Sci. 96, 7892-7903, https://doi.org/10.3168/ jds.2013-7128

Van Amburgh M.E., Collao-Saenz E.A., Higgs R.J., Ross D.A., Recktenwald E.B., Raffrenato E., Chase L.E., Overton T.R., Mills J.K., Foskolos A., 2015. The Cornell Net Carbohydrate and Protein System: Updates to the model and evaluation of version 6.5. J. Dairy Sci. 98, 6361-6380, https://doi. org/10.3168/jds.2015-9378

Van Amburgh M.E., Van Soest P.J., Robertson J.B., Knaus W.F., 2004. Corn silage neutral detergent fiber: Refining a mathematical approach for in vitro rates of digestion. In: Proceedings of the $66^{\text {th }}$ Cornell Nutrition Conference for Feed Manufacturers. Cornell University, Syracuse, NY (USA), pp. 99-108

Van Soest P.J., Robertson J.B., Lewis B.A., 1991. Methods for dietary fiber, neutral detergent fiber, and nonstarch polysaccharides in relation to animal nutrition. J. Dairy Sci. 74, 3583-3597, https://doi.org/10.3168/jds.S0022-0302(91)78551-2

Yang W.Z., Benchaar C., Ametaj B.N., Beauchemin K.A., 2010. Dose response to eugenol supplementation in growing beef cattle: Ruminal fermentation and intestinal digestion. Anim. Feed Sci. Technol. 158, 57-64, https://doi.org/10.1016/j.anifeedsci.2010.03.019 